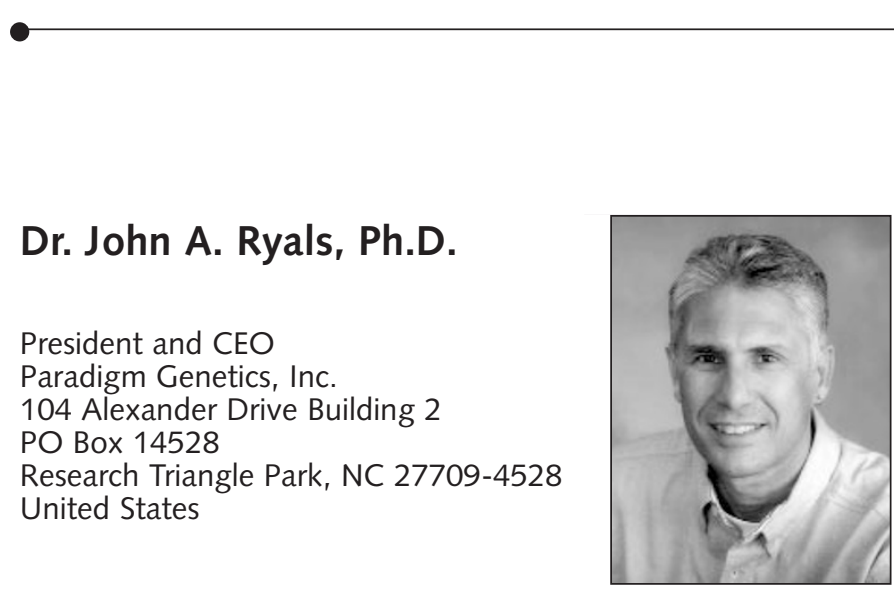

Dr. Ryals is a Founder of Paradigm Genetics, Inc. and serves as the Chief Executive Officer and President. Dr. Ryals received his Ph.D. in Molecular Biology from the University of Texas at Dallas in 1982. Before forming the company in 1997, he was Vice President of Research for Novartis Crop Protection, Inc. and Head of the Biotechnology and Genomics Center of Novartis in Research Triangle Park, North Carolina, where he was responsible for the worldwide biotechnology and genomics research and target-based discovery. Dr. Ryals has thirteen years of experience in agricultural biotechnology working in various positions at the Agricultural Biotechnology Research Unit of Ciba-Geigy Corporation including Head of Agricultural Biotechnology Research and Vice-President of Biotechnology at Ciba Seeds (1993-1996).

\section{A Functional Genomics Approach to Herbicide Discovery}

The technologies of structural and functional genomics promise to accelerate the pace of discovery in biology. In the pharmaceutical industry, these technologies have led to the identification of new drug targets and new drugs. In agriculture, these technologies should also have a dramatic impact on accelerating the pace of discovery. In particular, it should be reasonably straightforward to apply these technologies to small molecule discovery by identifying new, validated targets for herbicides. The approach I will discuss utilizes high-throughput DNA sequencing, high-throughput reverse genetics and knowledgebased computer systems to identify new targets for crop protection chemical discovery. 